\title{
A new unique form of microRNA from human heart, microRNA-499c, promotes myofibril formation and rescues cardiac development in mutant axolotl embryos
}

\author{
Andrei Kochegarov ${ }^{*}$, Ashley Moses, William Lian, Jessica Meyer, Michael C Hanna and Larry F Lemanski
}

\begin{abstract}
Background: A recessive mutation " $\mathrm{C}$ " in the Mexican axolotl, Ambystoma mexicanum, results in the failure of normal heart development. In homozygous recessive embryos, the hearts do not have organized myofibrils and fail to beat. In our previous studies, we identified a noncoding Myofibril-Inducing RNA (MIR) from axolotls which promotes myofibril formation and rescues heart development.

Results: We randomly cloned RNAs from fetal human heart. RNA from clone \#291 promoted myofibril formation and induced heart development of mutant axolotls in organ culture. This RNA induced expression of cardiac markers in mutant hearts: tropomyosin, troponin and a-syntrophin. This cloned RNA matches in partial sequence alignment to human microRNA-499a and b, although it differs in length. We have concluded that this cloned RNA is unique in its length, but is still related to the microRNA-499 family. We have named this unique RNA, microRNA499c. Thus, we will refer to this RNA derived from clone \#291 as microRNA-499c throughout the rest of the paper.
\end{abstract}

Conclusions: This new form, microRNA-499c, plays an important role in cardiac development.

Keywords: Myofibrillogenesis, Tropomyosin, Cardiac mutant axolotl, Human embryonic heart RNA, microRNA

\section{Background}

The Mexican axolotl, Ambystoma mexicanum, is an exciting and useful animal model to study vertebrate heart development and cardiac myofibrillogenesis. It carries a lethal cardiac recessive mutation, designated by gene "c", which, when homozygous $(\mathrm{c} / \mathrm{c})$, prevents normal heart development in axolotl embryos. Our previous studies [1] have shown that a non-coding RNA, MyofibrilInducing RNA (MIR) from normal axolotl, is capable of promoting myofibrillogenesis and beating hearts in the mutant (c/c) axolotl embryos. This study demonstrated that the MIR gene is essential for tropomyosin expression in axolotl hearts during development. Real-Time PCR studies showed that mRNA expression of various tropomyosin isoforms in untreated mutant hearts is similar to normal hearts knocked down with double-

\footnotetext{
* Correspondence: Andrei.Kochegarov@tamuc.edu

Department of Biological and Environmental Sciences, Texas A\&M UniversityCommerce, P.O. Box 3011, Commerce, TX 75429-3011, USA
}

stranded MIR (dsMIR). These results suggest that MIR is involved in controlling expression of various tropomyosin isoforms and subsequently in regulating cardiac contractility. The MIR was sequenced and found to be 166 nucleotides in length [2]. This RNA is unique in that it does not show significant homology to any known sequences in the online NCBI database. Comparison between MIR sequences obtained from normal and mutant embryos demonstrated a single point mutation at base 93 of the mutant MIR nucleotide sequence [2]. Genebee (Moscow State University), an online bioinformatics tool for the computation and modeling of secondary structures of RNAs, showed a conformational difference between the normal bioactive MIR and the mutant MIR, suggesting that the secondary structure of MIR might be important in the mutant rescue process [2]. More recently we have found that total human fetal heart RNA also has the ability to promote normal myofibril formation and restore function of the 
mutant axolotl hearts, suggesting that a functional homologue of the axolotl MIR could be present in human fetal heart tissue [3]. In the present study, through the random cloning of genes expressed in human heart, we have found a clone with the capacity to produce RNAs with the capability of promoting myofibrillogenesis and rescuing cardiac mutant axolotl hearts similarly to the axolotl MIR. We have designated this clone as a microRNA-499c. The role of microRNA-499 in heart development in human cardiomyocyte differentiation was previously described $[4,5]$. Our identification of the human microRNA which promotes myofibrillogenesis helps us to understand the molecular mechanism of heart development and may have important implications for future treatment of myocardial infarcts, cardiomyopathies and other congenital or acquired myocardial diseases in humans.

\section{Methods}

\section{Cloning}

For cloning, a total of $2 \mu \mathrm{g}$ of human fetal heart RNA (Agilent Technologies, Inc \#540165) was used for each reaction. The cloning kit used was the CloneMiner ${ }^{\mathrm{TM}}$ II cDNA Library Construction Kit (Invitrogen, \#A11180). First and second DNA strands were synthesized from template RNAs and ligated into the pDONR222 vector. The pDONR222 vector contains the kanamycin resistance gene which allows selection of transfected bacteria and the $\operatorname{ccdB}$ gene which interferes with E. coli DNA gyrase allowing negative selection of the donor vector in $E$. coli following recombination and transformation. The ElectroMAX ${ }^{\mathrm{TM}}$ DH10B $^{\mathrm{TM}}$ T1 Phage Resistant E. coli strain provided with the kit was transformed using the EC 1000 Electroporator (Thermo ES) at $2800 \mathrm{~V}$. To each sterile cuvette, $50 \mu$ l ElectroMAX ${ }^{\mathrm{TM}}$ DH10B cells, $1.5 \mu \mathrm{l}$ of $(150 \mathrm{ng} / \mu \mathrm{l})$ vector and $50 \mu \mathrm{l}$ of $\mathrm{dH}_{2} \mathrm{O}$ were added. In case the sample arced at this voltage setting, $100 \mu \mathrm{l}$ of $\mathrm{dH}_{2} \mathrm{O}$, or more, was added to increase electrical resistance. After electroporation, the cells were added to $1 \mathrm{ml}$ of S.O.C. medium and cultured in $15 \mathrm{ml}$ snap-cap tubes for at least 1 hour at $37^{\circ} \mathrm{C}$ on a shaker at 225-250 rpm to allow expression of the kanamycin resistance marker. Serial dilutions of sample aliquots with S.O.C. medium at the ratios 1:10, 1:100 and 1:1000 were plated on LB agar plates containing $50 \mathrm{ug} / \mathrm{ml}$ of kanamycin. The remaining cells were frozen at $-80^{\circ} \mathrm{C}$. Plated cells were incubated overnight at $37^{\circ} \mathrm{C}$. Individual colonies were collected and transferred into snapcap tubes with $2 \mathrm{ml}$ of $2 x Y T$ medium containing $50 \mathrm{ug} / \mathrm{ml}$ of kanamycin and incubated overnight. Plasmids with clones were extracted according to the standard Miniprep Plasmid DNA Isolation Protocol found in the online archive of the Institute of Bioinformatics and Applied Biotechnology.

\section{BsrGI digestion}

Extracted plasmids ( $5 \mu \mathrm{l}$ sample) were digested by $20 \mathrm{U}$ $(1 \mathrm{U} / \mu \mathrm{l})$ of enzyme BsrGI in $1 \mathrm{X}$ NE Buffer with $0.1 \mathrm{mg} / \mu \mathrm{l}$ of BSA. The mixtures were incubated for $1 \mathrm{~h}$ at $37^{\circ} \mathrm{C}$ and analyzed by Gel electrophoresis on 1\% agarose gels containing $0.5 \mu \mathrm{g} / \mathrm{ml}$ of ethidium bromide.

\section{PCR}

T7 RNA polymerase binding site TAATACGACTCACTA TAGGG was added to the $5^{\prime}$ end of forward and reverse M13 primers.

Forward primer: 5 -TAATACGACTCACTATAGGGGT AAAACGACGGCCAG-3'.

Reverse primer $5^{\prime}$-TAATACGACTCACTATAGGGCAG GAAACAGCTATGAC- $3^{\prime}$.

PCR was performed using a $\mathrm{MyTaq}^{\mathrm{TM}}$ Red Mix kit (Bioline, BIO-25043) according to the instruction manual for this kit: denaturation at $95^{\circ} \mathrm{C}$ during $15 \mathrm{sec}$ followed by annealing at $55^{\circ} \mathrm{C}$ for $15 \mathrm{sec}$ and elongation at $72^{\circ} \mathrm{C}$ for $15 \mathrm{sec}$ for 30 cycles. The resulting DNA was purified by $5 \mathrm{M}$ sodium chloride salt and isopropanol precipitation. Pellets were washed with $70 \%$ ethanol and re-suspended in $1 \mathrm{X}$ Tris-EDTA buffer.

\section{RNA synthesis}

The transcription reaction mixture was assembled from the MAXIscript ${ }^{\circledR}$ T7 Kit, Ambion \# AM1314M. Then, we added $1 \mu \mathrm{g}$ of DNA from the PCR product, $2 \mu \mathrm{L}$ of 10X transcription buffer, $2 \mu \mathrm{L}$ of T7 Enzyme Mix and $1 \mu \mathrm{L}$ of each $(10 \mathrm{mM}) \mathrm{NTP}$; and adjusted the volume to $20 \mu \mathrm{L}$ by nuclease-free water. The reaction mixture was incubated at $37^{\circ} \mathrm{C}$ for 2 hours. RNA was purified using ammonium acetate and ethanol precipitation and resuspended in nuclease-free water. The concentration of RNA was determined spectrophotometrycally at $260 \mathrm{~nm}$.using a Synergy HT (Bio-Tek) platereader.

\section{Bioassay}

Cardiac mutant non-function carrier $(+/ \mathrm{c})$ adult axolotls were obtained from the Ambystoma Genetic Stock

\begin{tabular}{lll}
$\begin{array}{l}\text { Table } 1 \text { Primers used for genes in real time RT-PCR } \\
\text { experiments }\end{array}$ & \\
\hline Gene of interest & Forward/ Reverse & Primer \\
\hline Tropomyosin & Forward & $5^{\prime}$-ggagcttgaccatgcgctgaa \\
Tropomyosin & Reverse & $5^{\prime}$-tgagaaccgacacaaagcaagagg \\
troponin T & Forward & $5^{\prime}$-ccaagggcttcaccgggctcaa \\
troponin T & Reverse & $5^{\prime}$-tggcagaggtggaatggatcacagg \\
a-syntrophin & Forward & $5^{\prime}$-ggactctccaccgcctccctctc \\
a-syntrophin & Reverse & $5^{\prime}$-ccccgcttcatccttcgctctga \\
$\beta$-actin & Forwar & $5^{\prime}$-tccatgaaggctgcccaact \\
$\beta$-actin & Reverse & 5 -tggcgccacatctgattgat \\
\hline
\end{tabular}




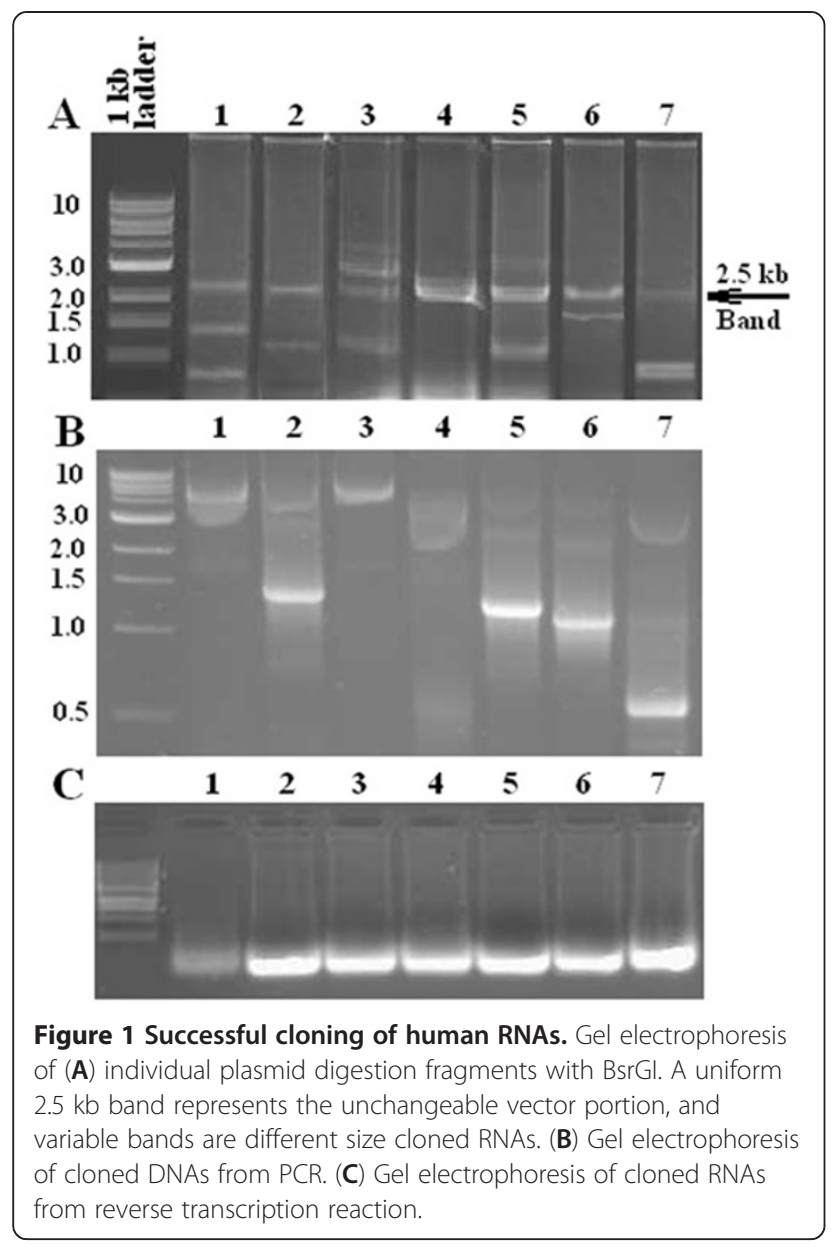

Center, University of Kentucky, Lexington. These heterozygous adult animals were mated $(+/ \mathrm{c} x+/ \mathrm{c})$ to produce mutant $(\mathrm{c} / \mathrm{c})$ and wildtype $(+/+)$ embryos for our studies. Embryos were collected and allowed to develop to heart-beat stages 35-36, according to the Bordzilovskaya et al. staging system [6]. For bioassays, only double recessive mutant c/c embryos were selected which do not have beating hearts. The embryos were anaesthetized by $0.7 \mathrm{mg} / \mathrm{ml}$ tricaine methanesulfonate or Ms-222 (Argeitt Chemicals Labs) in Holtfreter's solution [7]. Embryos were dissected under a binocular microscope in clay-lined Petri dishes in Holtfreter's medium containing 1\% antibiotic/antimycotic (Gibco \#15240). Hearts were transferred into the Petri dishes on Parafilm substrate into $50 \mu \mathrm{l}$ of Holtfreter's solution (without antibiotic) containing $7 \mathrm{ng} / \mu \mathrm{l}$ of human fetal heart RNA from individual clones along with $0.1 \mathrm{mg} / \mathrm{ml}$ of lipofectamine reagent (Invitrogen, Carlsbad CA). The Petri dishes with hearts were enclosed in a plastic container containing wet paper towels to maintain a saturated humidity environment at $17^{\circ} \mathrm{C}$.

\section{Fixation and staining procedure}

All steps were performed at room temperature as previously described [2]. Hearts were fixed in 4\% paraformaldehyde for $30 \mathrm{~min}$ and rinsed twice in PBS for $3 \mathrm{~min}$. Hearts were permeabilized in $0.05 \%$ Tween-20 and 3\% BSA in PBS for $1 \mathrm{~h}$. Hearts were incubated overnight with monoclonal anti-tropomyosin CG3 antibody (Developmental Studies Hybridoma Bank, University of Iowa) diluted to 1:75 in PBS, and then washed several times in PBS. Hearts were incubated in goat anti-mouse polyclonal secondary antibody (Abcam, \# ab6669) at a 1:75 dilution for $1 \mathrm{~h}$. The hearts were rinsed in several changes of PBS and mounted on slides in SlowFade ${ }^{\circledR}$ Gold antifade reagent (Invitrogen, \#S36936). Three layers of fingernail polish were applied to the edges of glass coverslips to prevent damaging of the whole hearts. Antibodies conjugated with FITC were excited at $488 \mathrm{~nm}$ with an emission at $520 \mathrm{~nm}$. The stained heart samples were scanned under a laser confocal microscope, Olympus Fluoview, equipped with a computer to record the images.

\section{qRT-PCR}

Normal and mutant embryonic hearts at stage 36-37 were placed into $15 \mu \mathrm{l}$ droplet cultures of Holtfreter's solution containing antibiotics [1]. Mutant hearts were
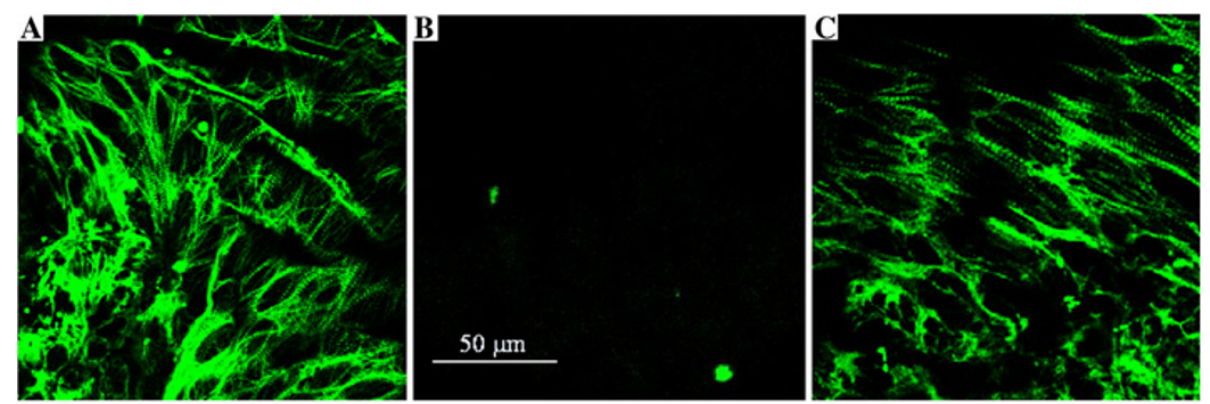

Figure 2 Tropomysin expression in RNA-treated mutant axolotl hearts revealed by immunofluorescent staining with confocal microscopy. (A) Normal heart. (B) Mutant untreated heart. (C) Mutant heart treated with cloned RNA (clone \#291) after 5 days of incubation in organ culture. Magnification is the same in all images. 


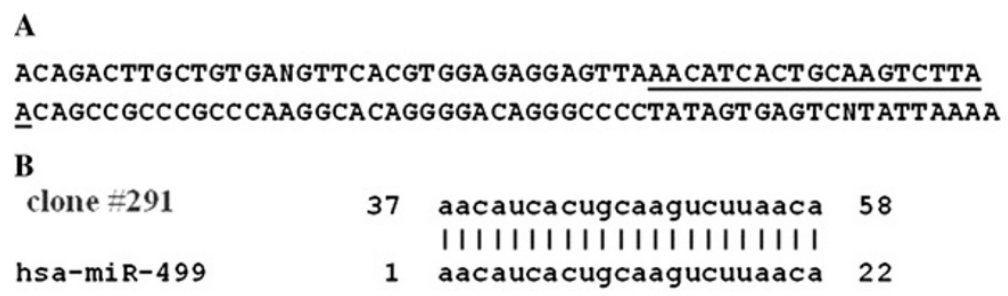

Figure 3 (A) DNA sequence of cloned RNA from the clone \#291 (microRNA-499c). Underlined area is 22 bp microRNA-499. (B) Alignment of cloned RNA with microRNA-499 generated in Mirbase [8].

placed in droplets containing $7 \mathrm{ng} / \mu \mathrm{l}$ of RNA derived from clone \#291 and incubated at $14^{\circ} \mathrm{C}$ for 72 hours. Each treatment group consisted of 10 hearts. RNA was extracted using a NucleoSpin RNAII Kit (Macherey-nagel) from ten mutant hearts treated with the active clone of human RNA (microRNA-499c), from 10 untreated (treated only with lipofectin) hearts as a control, and from ten normal hearts. qRT-PCR was performed with a Rotor-Gene machine using a Rotor-Gene SYBR PCR kit (Qiagen \#204074) with primers as reported in Table 1 [1]. Expression in normal heart was considered as $100 \%$. Expression was normalized (divided) by $\beta$ actin expression.

\section{Results and discussion}

On the basis of our results we hypothesize that normal human fetal heart expresses an RNA, which is a functional homologue to the axolotl MIR, and which probably is required for human heart development and function. Our results have clearly shown that if we clone this RNA from human fetal heart and transfect it into mutant axolotl hearts, normal heart development is restored. In an earlier publication, our laboratory showed that RNA extracted from human fetal and adult hearts, but not from skeletal muscle, rescued the development of mutant axolotl hearts in organ culture [3]. These earlier experiments suggest that total human heart RNAs, but not skeletal muscle, contain functional homologues of the MIR (myofibril-inducing RNA) derived from normal embryonic axolotl anterior endoderm [1].

A cDNA library was generated from total RNA extracted from human fetal heart that was purchased from Agilent Technologies Inc (Santa Clara, CA). We randomly cloned 400 individual RNAs from human fetal heart using the pDONR222 plasmid as a vector. DNA clones were synthesized by PCR using the vectors as templates and M13 primers. The PCR products were visualized through agarose gel electrophoresis and ethidium bromide staining. A vast majority of clones showed unique DNA bands (Figure 1B) indicating the presence of specific DNA inserts in the plasmids (Figure 1B). The RNAs were synthesized by using an in vitro transcription reaction and run on an agarose gel to test the result of the reaction (Figure 1C). RNA clones along with $0.1 \mathrm{mg} / \mathrm{ml}$ of lipofectamine transfection reagent were diluted to a concentration of $7 \mathrm{ng} / \mu \mathrm{l}$ in Holtfreter's solution containing a physiological mixture of salts required for cardiomyocyte contraction. The hearts were incubated in a plastic container at saturated humidity and room temperature. Each individual clone was tested on three hearts.

Transfection with RNA derived from clone \#291 was found to induce mutant hearts to beat. Initially, the treated hearts beat sporadically. However, with additional time in organ culture, the beating became more vigorous and regular. Hearts were fixed in paraformaldehyde and

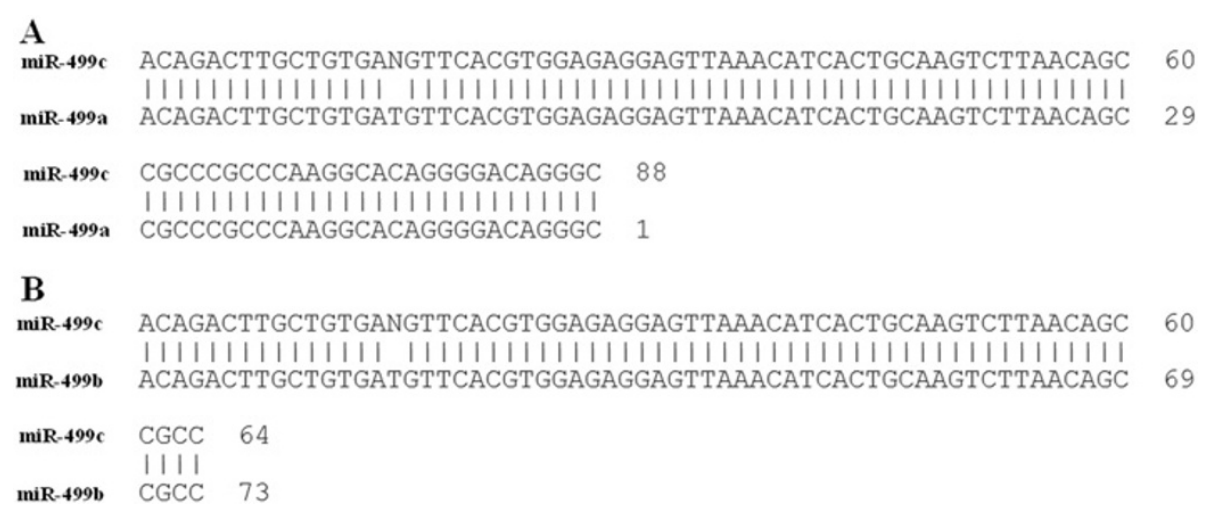

Figure 4 Alignment of cloned RNA (microRNA-499c) with (A) microRNA-499a and (B) microRNA-499b. 
stained with monoclonal anti-tropomyosin antibodies. Confocal microscopy revealed significant expression of tropomyosin in hearts treated with RNA derived from clone \#291 (Figure 2C). Mutant axolotl hearts, which were not treated with any RNA or with RNA derived from non-active clones, do not show tropomyosin expression and beating (Figure 2B).

The sequence analysis revealed a 111 bp long sequence of the cloned RNA (Figure 3A). We screened the sequence in Mirbase [8] and found that 22 bp microRNA-499 fragment is included in the cloned sequence (Figure 3B). Screening of the human genome database with the Basic Local Alignment Search Tool software (BLAST), on the NCBI website showed that the cloned sequence from clone \#291 is identical to an intron of one of the myosin heavy chain $(\mathrm{MHC})$ genes. Also we screened the online microRNA database, Mirbase [8], and we found homology with a 22 bp miR-499 fragment included in the cloned sequence (Figure $3 \mathrm{~B}$ ). There are two known forms of the microRNA-499 precursor: microRNA499a and microRNA-499b. Alignment of the cloned RNA, microRNA-499c, with precursors microRNA499a and microRNA-499b showed that although they differ in size, they have common and overlapping sequences (Figure 4B). Precursors of the microRNA, microRNA-499a has 122 bp, while microRNA-499b has only 73 bp and the newly discovered form, microRNA499c has 111 bp. Alignment showed that a new form
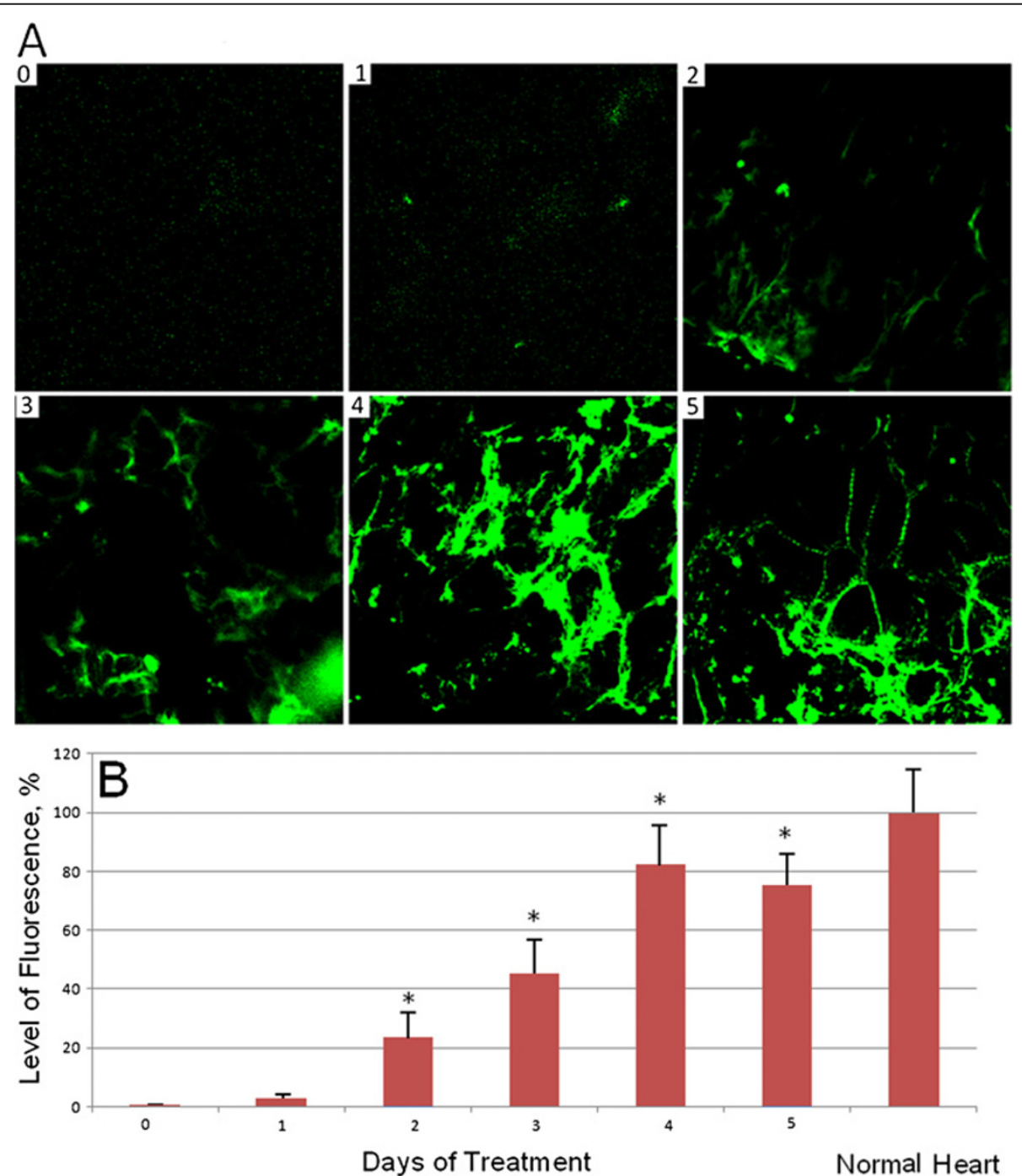

Figure 5 Time-course study of the relative quantities of tropomyosin expression by immunofluorescence staining in RNA-treated (7 $\mathbf{n g} / \mu \mathrm{l}$ of microRNA499c) axolotl hearts. A. The immunofluorescent images show mutant hearts that were fixed and stained for tropomyosin after incubation with $7 \mathrm{ng} / \mathrm{\mu l}$ of microRNA499c for 0, 1, 2, 3, 4 and 5 days; the 0 - control was without treatment. B. The average levels of fluorescence were quantified with ImageJ software as a percentage of that expressed in normal hearts, which was set to $100 \%$. Significance ${ }^{*} p$-value) between treated on the second day following days hearts and untreated hearts is $p<0.05, n=3$. 
of microRNA-499c has 88 common bp with microRNA499a and 66 common bp with microRNA-499b. Thus, we conclude that we have discovered a new form of microRNA-499 precursor, which we term microRNA-499c.

\section{Time-course experiment}

The hearts from mutant axolotl embryos were incubated with the microRNA-499c during different periods of time: 1, 2, 3, 4 and 5 days. Embryos at the time of dissection were at post-heart-beat stage 36-37. After incubation with RNA, the hearts were fixed and stained with anti-tropomyosin antibodies (Figure 5A). Fluorecsence levels of heart images were quantified with ImageJ software (National Institutes of Health) (Figure 5B). At the initial point, (0 days) the heart does not show tropomyosin expression. During the 4 days of incubation, tropomyosin expression gradually increases. Starting with day 2 and following days, significance between treated hearts and untreated hearts is less than $0.05(p<0.05, \mathrm{n}=3)$. Also, during the time increment of incubation, the numbers of striated myofibrils increases. Striated myofibrils are prominent by the $5^{\text {th }}$ day of RNA treatment of mutant hearts in organ culture, as well as in normal hearts (Figure 2A and $\mathrm{C}$ ).

\section{qRT-PCR}

RNA was extracted from ten mutant hearts treated with the active clone of RNA (7 ng/ $\mu$ l of microRNA-499c), from 10 untreated (treated only with lipofectin) mutant hearts as a control, and from ten normal hearts. Expression of genes considered as cardiac markers included: tropomyosin, cardiac troponin $\mathrm{T}$ and $\alpha$-syntrophin all of which increased significantly in comparison to $\beta$ actin in the RNA-treated hearts (Figure 6). Expression was calculated as \% of expression relative to normal hearts, which was assumed to be $100 \%$. In mutant hearts, expression of cardiac markers was much lower than in normal heart, as low as $10-20 \%$. After treatment with the active clone of RNA (7 ng/ $\mu$ l of microRNA499c), expression in mutant hearts increased significantly up to 70-90\%: tropomyosin $-75 \%$, cardiac Troponin $\mathrm{T}-70 \%$ and $\alpha-$ syntrophin - 90\%. Tropomyosin is an important protein in sarcomere formation and in muscle contraction [9]. Troponin is required to regulate $\mathrm{Ca}(2+)$-dependent contractions, and it was shown to be essential for sarcomere assembly in cardiac and skeletal muscles. The increased expression of these mRNAs suggests that the rescue of mutant hearts has taken place, when the muscle myofilaments start to be expressed and assemble into functional sarcomeric myofibrils. The increased expression of cardiac markers is consistent with data from our previous publication [1]. In that publication, expression of multiple cardiac makers: cardiac Troponin T, $\alpha$-syntropin and tropomyosin increased after 36 and 72 hours incubation with Myofibril-Inducing RNA (MIR) from axolotl. In the current experiment, this active clone of RNA from human heart (microRNA-499c) also increased expression of cardiac troponin T, $\alpha$-syntropin and tropomyosin.

Our results show that RNA cloned from human fetal heart has the capability of rescuing mutant axolotl hearts in organ culture bioassays. The rescue of mutant hearts
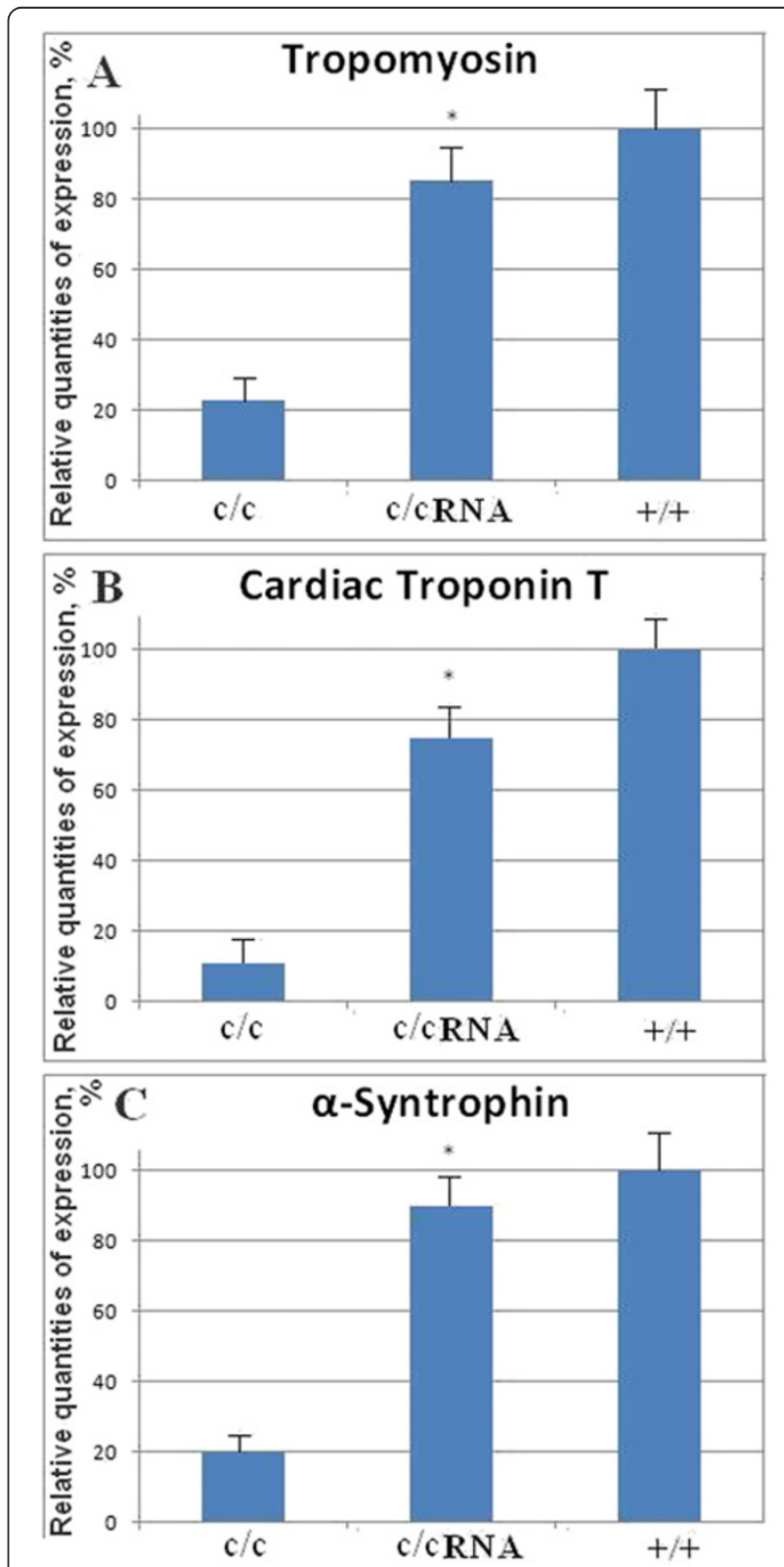

Figure 6 Relative expression of cardiac markers by RT-PCR in mutant hearts $(\mathrm{c} / \mathrm{c})$, mutant hearts transfected with the microRNA499c (c/c RNA) and normal hearts (+/+): (A) tropomyosin, (B) cardiac Troponin $\mathrm{T}$ and (C) a-syntrophin. Expression was calculated as percentage of that expressed in normal hearts (expression in normal hearts was assumed as 100\%). Significance between treated and untreated mutant hearts is for tropomyosin, $p<0.05$, cardiac Troponin T $p<0.02$ and a-syntrophin $p<0.03, \mathrm{n}=10$. 
was demonstrated by the development of beating in the hearts and expression of tropomyosin in organized myofibrils after incubation with the microRNA-499c. All three microRNA-499 precursors apparently originate from the same intron, which is initially the intron of the myosin heavy chain (MHC) genes.

The human microRNA-499 belongs to a family of micro RNAs encoded by the intron of the myosin heavy chain (MHC) genes, referred to as MyomiRs which also include microRNA-208a and microRNA-208b. MicroRNA499 is highly conserved, being present in the genome of many vertebrate species (human, mouse, rat, bovine, Xenopus and zebrafish) [10]. Micro-RNAs are noncoding RNAs which regulate the translation of genes by binding to untranslated sites (UTRs) in their targets. Nascent precursor microRNAs are usually about one hundred or more nucleotides long, and later, microRNAs are split by enzymes into a short active $22 \mathrm{bp}$ fragment.

In animals, expression of microRNAs occurs in two stages. First, in the nucleus, pre-microRNAs are cleaved from an extended primary transcript of the gene which then is exported to the cytoplasm of the cell. In the cell cytoplasm, endoribonuclease, called Dicer, cleaves the double-stranded RNA (dsRNA) into a short 22 nucleotide micro-RNA. The mature microRNA is incorporated into the RNA-induced silencing complex (RISC) which includes Dicer and other proteins. The miRNA binds complementary mRNAs and directs them to degradation by endonucleases or prevent their translation by holding them in the RISC. In situ hybridization analysis of mouse heart, brain, spleen, liver, lung, quadriceps muscle, kidney, and gut tissues shows that the mature microRNA-499 is abundantly expressed in cardiac tissue and almost absent in other tissues, including skeletal muscle [10]. Some of those predicted targets of microRNA-499 and microRNA1 were shown to regulate cardiomyocyte differentiation. Transient transfection of microRNA-1 and -499 in human cardiomyocyte progenitor cells (CMPCs) reduced the proliferation rate and increased differentiation into cardiomyocytes. This effect most likely occurs by repression of histone deacetylase 4 or Sox6 because levels of these proteins are reduced [10]. It has been found that microRNA-499 promotes ventricular specification in differentiating human embryonic stem cells [11]. It was shown further that microRNA-499 expression increased in human stem cells differentiating into cardiomyocytes. Also, microRNA-499 transduction by the lentivirus of hESC-derived cardiovascular progenitors significantly increased the yield of stem cell-derived ventricular specified cardiomyocytes [11]. Other results suggest that expression of microRNA-499 in human cardiac stem cells (hCSCs) represses the microRNA-499 target genes Sox6 and Rod1, enhancing cardiomyogenesis in vitro and after infarction in vivo [5]. The level of
microRNA-499 was 400 times higher in cardiomyocytes than in rat cortical stem cells. Cardiomyocytes derived from differentiation of hCSCs treated with microRNA-499 appeared to be larger, and their sarcomere striations were more evident [5]. Expression of microRNA-499 was observed to be increased a few hundred times during differentiation of human embryonic stem cells into beating clusters [4]. Also, overexpression of microRNA499 enhanced expression of myocyte-specific enhancer factor $2 \mathrm{C}$, the transcription factor which is involved in cardiac morphogenesis and myogenesis and vascular development [4]. Thus, microRNA-499 appears to play an important role during heart development, although the molecular mechanisms and the microRNA-499 pathways are not well understood at this time.

\section{Conclusion}

Our results demonstrate clearly and unequivocally that human-derived microRNA-499c promotes the formation of cardiac myofibrils in cells of cardiac mutant salamander hearts and thus restores normal embryonic heart development in these lower vertebrate species. This observation is consistent with earlier publications showing that microRNA-499 plays an important role in cardiac differentiation and cardiogenesis during embryonic development, and it strongly suggests a ubiquitous and conserved mechanism of classic embryonic heart induction $[12,13]$ and myofibrillogenesis across the spectrum of vertebrate species.

\section{Competing interests}

The authors declare no competing interests.

\section{Authors' contribution}

LFL served as the Principle Investigator on the study and on the American Heart Association and NIH grants that supported the study. LFL and AK planned and oversaw all of the experiments and coordinated the research activities of the study. AK wrote the final draft of the manuscript. LFL edited the entire manuscript. AM and AK performed the bulk of the experiments while $\mathrm{WL}$ and JM helped with many experiments. MCH consulted, advised in molecular biology techniques and helped to interpret many findings. All authors read and approved the final manuscript.

\section{Acknowledgments}

This work is supported by an NIH grant (HL061246) and an American Heart Association grant (10GRNT4530001) to LFL and an NSF-RUI Award (1121151) to $\mathrm{MH}$

Received: 3 December 2012 Accepted: 18 March 2013 Published: 23 March 2013

\section{References}

1. Zhang C, Jia P, Huang X, Sferrazza GF, Athauda G, Achary MP, Wang J, Lemanski SL, Dube DK, Lemanski LF: Myofibril-inducing RNA (MIR) is essential for tropomyosin expression and myofibrillogenesis in axolotl hearts. J Biomed Sci 2009, 16:81.

2. Zhang C, Dube DK, Huang X, Zajdel RW, Bhatia R, Foster D, Lemanski SL, Lemanski LF: A point mutation in bioactive RNA results in the failure of mutant heart correction in Mexican axolotls. Anat Embryol 2003, 206:495-506.

3. Rueda-de-León E, Kochegarov A, Lian W, Athauda G, Zhang C, Maier J, Huang X, Achary MP, Moses A, Meyer J, Arms JD, Burlbaw SR, Lemanski SL, Lemanski 
LF: Human Heart RNA Promotes Tropomyosin Synthesis and

Myofibrillogenesis in Mutant Axolotl Hearts. MD-Med Data 2011, 3:223-227.

4. Wilson KD, Hu S, Venkatasubrahmanyam S, Fu JD, Sun N, Abilez OJ, Baugh JJ, Jia F, Ghosh Z, Li RA, Butte AJ, Wu JC: Dynamic microRNA expression programs during cardiac differentiation of human embryonic stem cells: role for miR-499. Circ Cardiovasc Genet 2010, 3:426-435.

5. Hosoda T, Zheng H, Cabral-da-Silva M, Sanada F, Ide-Iwata N, Ogórek B, Ferreira-Martins J, Arranto C, D'Amario D, del Monte F, Urbanek K,

D'Alessandro DA, Michler RE, Anversa P, Rota M, Kajstura J, Leri A: Human cardiac stem cell differentiation is regulated by a mircrine mechanism. Circ 2011, 123:1287-1296.

6. Bordzilovskaya NP, Dettlaff TA, Duhon ST, Malacinski GM: Developmentalstage series of axolotl embryos. In Developmental Biology of the Axolotl. Edited by Armstrong JB, Malacinski GM. New York: Oxford University Press; 1989:201-219.

7. Lemanski LF, Nakatsugawa M, Bhatia R, Erginel-Unaltuna N, Spinner BJ, Dube DK: A specific synthetic RNA promotes cardiac myofibrillogenesis in the Mexican axolotl. Biochem Biophys Res Com 1996, 229:974-981.

8. Mirbase, micro RNA database. www.mirbase.org.

9. Lemanski LF: Role of tropomyosin in actin filament formation in embryonic salamander heart cells. J Cell Biol 1979, 82:227-238.

10. Sluijter JP, van Mil A, van Vliet P, Metz CH, Liu J, Doevendans PA, Goumans MJ: MicroRNA-1 and -499 regulate differentiation and proliferation in human-derived cardiomyocyte progenitor cells. Arterioscler Thromb Vasc Biol 2010, 4:859-868.

11. Fu JD, Rushing SN, Lieu DK, Chan CW, Kong CW, Geng L, Wilson KD, Chiamvimonvat N, Bohele KR, Wu JC, Keller G, Hajjar RJ, Li RA: Distinct roles of microRNA-1 and -499 in ventricular specification and functional maturation of human embryonic stem cell-derived cardiomyocytes. PLoS One 2011, 6:e27417.

12. Jacobson AG, Duncan JT: Heart induction in salamanders. J Exp Zool 1968, 167:79-103.

13. Fullilove SL: Heart inductor: distribution of active factors in newt endoderm. J Exp Zool 1970, 75:323-326.

doi:10.1186/1423-0127-20-20

Cite this article as: Kochegarov et al:: A new unique form of microRNA from human heart, microRNA-499c, promotes myofibril formation and rescues cardiac development in mutant axolotl embryos. Journal of

Biomedical Science 2013 20:20.

\section{Submit your next manuscript to BioMed Central and take full advantage of:}

- Convenient online submission

- Thorough peer review

- No space constraints or color figure charges

- Immediate publication on acceptance

- Inclusion in PubMed, CAS, Scopus and Google Scholar

- Research which is freely available for redistribution 